\title{
¿Cómo negociar la política migratoria de México? Prácticas, logros, errores y opciones
}

\author{
How can the migratory policy of Mexico be negotiated? \\ Methods, gains, errors and options
}

Rodolfo Casillas R.*

ISSN IMPRESO 1870-7599 | ISSN RED CÓMPUTO 2448-7783 | 7-36 RECIBIDO 01/12/20 | ACEPTADO 17/12/20

Resumen. Desde una perspectiva regional y de realpolitik, los procesos migratorios que ocurren y transitan por México deben ser vistos desde una articulación política de economía, seguridad y migración con Estados Unidos. En este texto se analiza cómo ha ocurrido dicho proceso, cuáles son las expectativas mexicanas y estadounidenses, qué logros ha habido y cuáles son los costos y errores estratégicos del lado mexicano. Se concluye con una propuesta concreta de cómo esa relación desventajosa para México con su contraparte estadounidense puede ser modificada revalorando las cartas en juego y los términos en que se realizan las negociaciones.

Palabras clave: migración, seguridad nacional, economía, negociación, Estados Unidos, México.

\begin{abstract}
As viewed from a regional perspective, and that of realpolitik, the migratory process that occur within and pass through Mexico must be considered on a basis of political economy, security and migration with the United States. This text analyzes how said processes have taken place, which are the expectations of Mexicans and citizens of the United States, what achievements have been attained and what costs and strategic errors affected Mexico. It concludes with a concrete proposal of how this disadvantageous position for Mexico with its U.S. counterpart can be modified, to reshuffle the cards in play and the terms under which negotiations are conducted.
\end{abstract}

Keywords: migration, national security, economy, negotiation, United States, Mexico.

\footnotetext{
${ }^{*}$ Mexicano. Profesor e investigador de la Facultad Latinoamericana de Ciencias Sociales (Flacso), México. Correoe: rodolfo.casillas@flacso.edu.mx
} 


\section{Planteamiento del problema}

¿Puede México tener una política migratoria propia, independiente de las necesidades y expectativas de Estados Unidos? Si la tiene, ¿qué elementos verificables podrían mostrar su independencia y autonomía? Si no la puede tener, ¿qué política puede desarrollar que, sin que le signifique un conflicto con la potencia vecina, satisfaga los compromisos internacionales de derechos humanos, de buena vecindad con los países del sur y de cauces satisfactorios a los migrantes internacionales, propios y no? ¿Es eso posible? En todo caso, ¿cuál es la importancia que tiene la migración para el gobierno de México? $\bigcirc$, desde una perspectiva más amplia, ¿qué peso tiene la migración internacional en la política de crecimiento poblacional de México? Todavía más, entre las prioridades gubernamentales de México, ¿qué lugares ocupan la población y la migración en el supuesto de que formen parte de ellas?

Cualesquiera que sean las respuestas, la pregunta primera debe responderse de forma obligatoria, sin evasivas. No hay margen o, si lo hay, lo impone Estados Unidos. Con ello, de manera implícita avanzó la idea de que la política migratoria del gobierno de México tiene, forzosamente, que considerar el establecimiento de acuerdos con Estados Unidos en la materia, algo que ya ocurre desde hace decenios. En consecuencia, ante la política migratoria de la administración Trump, que evidenció de manera más que grosera su fuerza, y la política obsecuente aplicada por el gobierno de México de modo inmediata, que mostró no sólo su fragilidad sino la ausencia de creatividad, cabe preguntarse: ¿debe México seguir esa ruta, en los términos y condiciones en que lo hace, o debe replantearse dichos términos, condiciones y la ruta misma? En este texto presento de manera sintética un conjunto de análisis y reflexiones en torno a las interrogantes antes planteadas que, en aras de la verdad, merecerían al menos un libro extenso de argumentaciones.

\section{Crecimiento poblacional y migración}

Fue durante el gobierno de Luis Echeverría (1970-1976) cuando México pasó de «los hijos que Dios me dé» al inicio de la planificación familiar. Con esa planificación, enmarcada en una amplia serie de medidas diversas (creación de dependencia especializada, personal, infraestructura, presupuesto, etcétera), las autoridades 
mexicanas empezaron a modular el crecimiento poblacional. Es decir, reducir el número de hijos por pareja y que los hijos no llegaran a edades tan tempranas. De esa forma el crecimiento natural de la población mexicana en el mediano y largo plazo tendió, con buenos resultados, a hacer realidad una consigna del Consejo Nacional de Población: la familia pequeña vive mejor, en la que en imagen aparecen un par de adultos, una niña y un niño, con lo que también se hablaba de cierto equilibrio de sexos. En lo que va del siglo XXI puede decirse que el crecimiento poblacional del país, al menos por el lado del crecimiento natural, no constituye un problema que preocupe a las autoridades gubernamentales, lo que no implica dejar de mantener la idea de pocos hijos por pareja.

El otro componente de cómo se comporta el crecimiento de un país es la migración internacional, lo que se considera el crecimiento social de una población determinada. Ésta cuenta con al menos dos componentes centrales: la emigración de mexicanos y la inmigración de extranjeros. Una fuerte emigración afecta dicho crecimiento, aunque se mantenga un número elevado de hijos independientemente de la edad en que se tengan; si se tienen a edades tempranas hay otro tipo de efectos sociales que luego mencionaré. En el caso de México, la fuerte emigración de nacionales a Estados Unidos ralentizó el crecimiento poblacional, el cual llegó a su momento climático cuando al término del primer quinquenio del siglo XXI se estimó que medio millón de mexicanos se quedaban al año en el país vecino. Al siguiente quinquenio se estimó que el saldo migratorio era cero y para 2020 hay indicios de que la tendencia empieza a cambiar. Es probable que a partir de 2021 se conjuguen de nuevo las nuevas condiciones en Estados Unidos, con un nuevo presidente y con las circunstancias agravadas en la economía mexicana, para que esa tendencia cobre fuerza. Sin embargo, aún no hay elementos suficientes que permitan realizar un pronóstico más preciso.

Históricamente, la inmigración en México ha sido insignificante como valor número relativo: menos de 1 por ciento de la población total (INEGI, 2015). Incluso, un análisis de la composición del total de la población captada como estadounidense, la extranjería más numerosa de todas, desagregando la doble nacionalidad, indica un alto porcentaje de mexicanos en esa circunstancia, lo que reduce el número de extranjeros inmigrantes captados en el registro oficial (Rodríguez, 2012). Pese a que en los últimos años se observa una mayor presencia de centroamericanos, tanto en el Censo de 2010 como en la Encuesta intercensal de 2015, y en fuentes hemerográficas e informes varios posteriores a ese año, sea por las caravanas de migrantes o aquellos que esperan en suelo mexicano la resolución 
a su petición de refugio en Estados Unidos, con el saldo de quienes decidan quedarse de ambos flujos, ni aún así el valor relativo de inmigrantes extranjeros significa un crecimiento exponencial de consideración. Es decir, el resultado del total de flujos migratorios internacionales no representa en el presente ni en el futuro cercano una fuente de preocupación relativa al crecimiento poblacional. En consecuencia, tampoco ésta sería una prioridad para las autoridades gubernamentales del país.

¿Cuál sería el flujo migratorio internacional que sí le preocupa y le seguirá preocupando al gobierno de México? El flujo mixto de extranjeros de paso por el país, ${ }^{1}$ el cual debe atenderse con prioridad por dos razones, una interna y otra internacional. La interna, porque en la medida en que el flujo o sus remanentes se estanquen en algunos sitios puede ser motivo de tensión entre autoridad federal y autoridad estatal o municipal. La externa, Estados Unidos, que es parte esencial del tema que aquí desarrollo.

\section{Antecedente inmediato}

Desde que se formó como Estado nación, a los inicios del siglo XIX, México se pronunció por el desarrollo y progreso económicos. Con esa perspectiva buscó una inmigración extranjera selectiva: empresarios, técnicos e inversionistas que vinieran a fortalecer la economía nacional, con sus capitales, conocimientos técnicos o experiencia empresarial, como quedó plasmado en las leyes de la época (Instituto Nacional de Migración, 1996). A finales del siglo XIX, los lugares posibles de donde podrían venir personas con esas características eran de las potencias europeas y Estados Unidos. En esencia, ese objetivo económico se ha mantenido vigente hasta el presente, si bien a comienzos del siglo XXI se amplió el horizonte potencial de procedencia. ${ }^{2}$ No obstante, desde 1994 se hizo

\footnotetext{
${ }^{1}$ Se le llama flujo migratorio mixto al que se compone, de manera indistinta, por migrantes económicos; por aquellos expulsados y desplazados por problemas de inseguridad pública; por solicitantes de refugio rechazados; deportados de Estados Unidos que pretenden volver a ese país; parejas sentimentales y descendientes que van tras la reunificación familiar; mujeres jóvenes que buscan su propio futuro; niñas, niños y adolescentes que viajan solos o acompañados, etcétera.

${ }^{2}$ Para el estudio de la evolución de las disposiciones migratorias de México en el siglo XX y lo que va del XXI véase: Ley de Inmigración de 1909; Ley de Inmigración de 1926; Ley de Inmigración de 1930; Ley General de Población de 1936; Ley de General de Población de 1947; Ley de General de Población de 1974; creación el 19 de octubre de 1993 del Instituto Nacional de Migración (INM); Ley General de Población
} 
una opción preferencial con la firma del Tratado de Libre Comercio con Estados Unidos y Canadá, conocido como el TLCAN. En julio de 2020 se reafirmó esa preferencia con el inicio de actividades del sucesor del TLCAN, el T-MEC, que incluye a los mismos países del norte continental pero ya no es de libre comercio.

En 1994 México prefirió que el tema de la migración internacional quedara fuera de la negociación del Tratado, porque la migración mexicana a Estados Unidos estaba al alza. Para Estados Unidos el tema de la seguridad nacional cobró un nuevo brío claramente relacionado con la migración internacional a partir del ataque recibido en su territorio en 2001. ${ }^{3}$ Mientras uno buscaba cómo vincularse más de forma estructural con la economía mundial vecina, el otro andaba cuidándose de los ataques de sus enemigos. Para la negociación del T-MEC México llegó con menor presión en lo relativo a la migración mexicana en Estados Unidos porque su saldo migratorio era cero y aceptó que ese tema formara parte de la agenda, a pesar de que las noticias que se difundieron sobre las reuniones técnicas y ministeriales sólo hicieron referencia a los contenidos económicos. El tema migratorio no fue olvidado ni quedó ausente, simplemente fue parte de una agenda paralela, la de la seguridad estadounidense, cuyas implicaciones profundas serán abordadas en los siguientes segmentos.

En tanto que el saldo migratorio mexicano es prácticamente cero a partir del segundo decenio del siglo XXI, las prioridades de México con Estados Unidos en materia migratoria siguen siendo importantes, aunque de otra naturaleza y tratamiento: a) regularización de la población indocumentada mexicana en

de 1996; decreto por el cual el INM es convertido en instancia de seguridad nacional en 2005; Ley de Migración 2011 y reformas posteriores en 2017.

${ }^{3}$ A consecuencia de los ataques del 11 de septiembre de 2001, Estados Unidos modificó su política migratoria con una nueva ingeniería institucional y con nuevas disposiciones y criterios para el otorgamiento de visas de ingreso, condiciones de estadía, etcétera. Entre las medidas tomadas destacan las siguientes disposiciones legales: Acta Patriótica, 2001, que triplica el personal de inspección migratoria, aduanas y patrulla fronteriza en frontera con México, incrementa el presupuesto para equipamiento tecnológico y refuerza las regulaciones para impedir el acceso de posibles terroristas; Acta sobre Ampliación de la Seguridad y Reforma de las Visas de entrada, 2002 (EBSVERA); Programa de Seguridad Nacional de Registro de Entrada y Salida, 2002 (NSEERS); Programa USA-Visit, 2003 (Visitor \& Inmigrant Status Indicator Technology); Student \& Exchange Visitor Information System, 2003 (SEVIS); Alianza para la Seguridad y la Prosperidad de América del Norte, marzo de 2005 (ASPAN), de Canadá, Estados Unidos y México; Programa bilateral México-Estados Unidos para la Persecución de Traficantes de Migrantes (Programa OASIS), agosto de 2005; Iniciativa de Fronteras Seguras, USA, noviembre de 2005, nuevo nivel de prioridad en el combate a la migración indocumentada; The National Security Strategy of the USA, marzo de 2006. 
Estados Unidos; b) establecimiento de programas de trabajadores temporales, un tema de importancia variable; c) devoluciones seguras, dignas y ordenadas; d) seguridad fronteriza en la lógica de evitar el trasiego de armas y de dinero ilícito; e) gestión sobre el número y características de visas (trabajadores temporales); yf) programa de promoción al desarrollo en regiones con altos índices de emigración internacional. La agenda migratoria de Estados Unidos con México sería: 1. Seguridad regional en la lógica del trasiego de drogas y terrorismo. 2. Control fronterizo. 3. Regulación de todos los flujos migratorios, en particular los mixtos e indocumentados. 4. Registros estadísticos compartidos de migrantes documentados e indocumentados, incluyendo datos biométricos. 5. Acciones conjuntas para la prevención y detención de los flujos indocumentados. Como puede apreciarse, las agendas migratorias de ambos países siguen siendo complejas y no tienen los mismos temas, enfoques ni prioridades; no obstante, no parece haber diferencias mayores en lo referente a la migración indocumentada de paso, ${ }^{4}$ liderada por los nacionales del norte centroamericano, que viven serios problemas estructurales (Canales y Rojas, 2018; Canales et al., 2019).

A la administración de Barak Obama le siguió la de Donald Trump que, de inmediato, expidió tres órdenes presidenciales (la Border Security and Immigration Enforcement Improvements; la Enhancing Public Safety in the Interior of the United States; y la Protecting The Nation From Foreign Terrorist Entry To The United States; dos el 25 de enero 2017 y la tercera el 29) que hicieron más restrictivo el acceso y estadía en el país, en específico para algunas nacionalidades consideradas proterroristas, sin dejar de lado los reiterados señalamientos de construir un muro a lo largo de la frontera sur estadounidense, ${ }^{5}$ aparte de aplicar otras disposiciones aplicables a migrantes extranjeros residentes en Estados Unidos.

\footnotetext{
${ }^{4}$ En especial en México se le llama migrante indocumentado al extranjero que migra, transita, ingresa o reside en un país que no es el suyo, sin contar con la autorización migratoria correspondiente. Esta concepción mexicana, en su formulación jurídica, clasifica al migrante indocumentado como un infractor administrativo y, en consecuencia, no amerita reclusión penal, una medida legal para quienes cometen actos criminales. En Estados Unidos un migrante sin la autorización legal correspondiente sí comete un acto criminal, de ahí que sea recluido en cárceles, con el trato correspondiente, lo que facilita su expulsión del suelo estadounidense.

${ }^{5}$ Casi 3 mil 200 kilómetros de frontera entre Estados Unidos y México, que incluyen 48 condados estadounidenses y 94 municipios mexicanos, con una población aproximada de 13 millones de habitantes en 2016, distribuida en diez áreas metropolitanas transfronterizas. Por esa frontera cada día se realizan más de un millón de cruces legales de personas y alrededor de 300 mil de vehículos, de ellos 70 mil son camiones de carga, que transitan por 53 puentes y garitas. Esta frontera es la más transitada del mundo occidental (Hernández, 2020).
} 
En ese contexto hubo un hecho significativo que mostró que en los temas de migración y seguridad había un acuerdo entre Estados Unidos y México en tratarlos de manera relacional y en la medida de lo posible en privado. El canciller mexicano se reunió con la jefa del Comando Norte y el jefe del Comando Sur de Estados Unidos, en la ciudad de Tapachula el martes 31 de enero de 2017, según medios de información (The Washington Post y Milenio, 1 y 4 de febrero, respectivamente). Un encuentro inicialmente negado por el gobierno mexicano que, luego de filtraciones estadounidenses, acabó por ser reconocido por aquel.

El proceder del gobierno mexicano dio lugar a suspicacias y preguntas incómodas. La primera preguntar fue: ¿cuál era la competencia legal del canciller para tratar el tema migratorio, competencia de la Secretaría de Gobernación de acuerdo con el marco jurídico, y el titular de dicha dependencia no participó en ese encuentro? Lo segundo: resultó llamativo que comandantes del ejército estadounidense asistieran a esa reunión privada para hablar de migración, cuando tampoco es su competencia ni ocupación, dado que el Homeland Security y el ICE son las instancias competentes. La tercera: un canciller que dialoga con comandantes en lugar de hablar con su par en jerarquía, es decir, el titular del Departamento de Estado de Estados Unidos, o el titular del Homeland Security en su caso. Es inusual que el canciller de un país tome acuerdos con comandantes del ejército de otro país, en una materia que legalmente no es competencia ni de uno ni de otros. El tema, en consecuencia, era el de seguridad y la migración asociada a él, y desde un punto de vista operativo, de ahí que fueran comandantes de Estados Unidos para recalcar que lo que el presidente Trump buscaba eran acuerdos operativos y de aplicación inmediata. Adicionalmente hay otra pregunta: ¿cuál es la competencia del canciller mexicano para hablar de seguridad cuando ese tema también le corresponde a la Secretaría de Gobernación? La única explicación plausible es que el presidente mexicano dotó al canciller de poderes metalegales y el titular de Gobernación, como el resto del gabinete, asumió con disciplina la decisión presidencial y guardó silencio. Prevaleció el interés en cuidar la relación con Estados Unidos por encima del apego al marco legal nacional en el ánimo presidencial. Por otro lado, no hay que olvidar que el régimen mexicano es presidencialista, por lo que no resultan extraños esos excesos en el gobernar, cuando se instruye a un secretario lo que le corresponde legalmente a otro. El clima electoral candente y el resultado de la elección presidencial a mediados de 2018 ocuparon la opinión pública. El tema migratorio pasó a espacios secundarios en la opinión pública, pero no los acuerdos tomados por el gobierno de México con el de Estados Unidos. 
Los acuerdos preexistentes relativos a los aspectos de seguridad y economía vinculados a la migración internacional se mantuvieron inalterables durante los primeros meses de la administración Trump y los últimos de la administración Peña Nieto. Para ambas el volumen creciente de migrantes centroamericanos era materia de atención. Desde la administración de Obama, Estados Unidos manifestó de modo reiterado su preocupación por la llegada de más migrantes, en particular lo hizo con la llamada "crisis humanitaria» en 2014 (Pew Research Center, 2017). En el gobierno mexicano se tenían dos preocupaciones: a) cómo el tema de la migración centroamericana podría gravitar y afectar las negociaciones de lo que sería el T-MEC, yb) las implicaciones internas en seguridad pública por la presencia de más centroamericanos en el país que, como solicitantes de refugio ${ }^{6}$ o como migrantes que «se quedaban», engrosaban el total estimado de centroamericanos; este segundo argumento fue expresado en concreto por altas esferas del INM en reuniones privadas y luego confiadas al autor de este texto por participantes que prefirieron permanecer en el anonimato.

En síntesis, eran dos los flujos migratorios que preocupaban a las dos administraciones nacionales: el flujo mixto en tránsito por México (CEM/UPM, 2017) y con destino a Estados Unidos, y el flujo creciente de solicitantes de refugio (Amnistía Internacional, 2018). Para las dos administraciones lo mejor era que la migración al norte continental de centroamericanos de Guatemala, Honduras y El Salvador no ocurriera, o que lo hiciera de manera ordenada, segura y legal, es decir, bajo administración plena de los países de tránsito y destino: México y Estados Unidos. Cómo hacerlo posible sin aplicar nuevas medidas selectivas para el otorgamiento de visas y la aplicación de controles para la detección, detención y devolución de migrantes extranjeros indocumentados, era la pregunta sin respuesta.

Las caravanas de migrantes centroamericanos, que iniciaron en octubre de 2018, iniciaron una nueva forma de viajar en masa mixta de nacionalidades, preferencias sexuales y edades: todos indocumentados, baja calificación educativa y laboral, con bolsillos llenos de ilusiones y no más (Chávez, 2019; Torre y

${ }^{6}$ Los solicitantes de refugio en México provienen, en su mayoría, de uno de los tres países del norte de Centroamérica: Honduras, El Salvador y Guatemala. Los procesos políticos y la delincuencia urbana presente en estos tres países son algunos de los factores que llevan a su población a solicitar protección en distintos escenarios (Martínez, 2010; 2016). Por otro lado, debido a la crisis económica y política de Venezuela, su población es uno de los colectivos con mayor número de solicitudes de refugio en México en los dos últimos años. Cuba y algunos países del Caribe como Haití son otros lugares de origen de los solicitantes de refugio (UNHCR, 2018). 
Mariscal, 2020; Ruiz y Varela, 2020; Camus et al., 2020). Nutridos grupos de haitianos llegaron a la frontera mexicana con la estadounidense, luego de haber cruzado, en bastantes casos, por más de 10 países (París, 2018). Las caravanas multinacionales llegaron con relativa facilidad a la frontera sur mexicana, cruzaron con cierta rapidez y apoyos varios por México y se concentraron en puntos estratégicos de la frontera norte mexicana, situación que prendió las alarmas estadounidenses, mientras en México se festinaba/temía el cambio de administración federal. Una nueva «invasión» de las tierras del Tío Sam había iniciado.

\section{Continuidades y redefiniciones}

La postura wasp (white anglo saxon protestant) y de inmigración altamente selectiva del presidente Trump ya era conocida en 2018, con antecedentes sociales inocultables (Velazco, 2016). No obstante, el nuevo gobierno de México inició labores al enunciar una política pro migrante y de otorgamiento de visas humanitarias, que en menos de un año revirtió. En unos cuantos meses transitó por tres actuaciones distintas: a) otorgamiento de visas humanitarias (diciembre de 2018 a marzo 2019); b) los reclamos estadounidenses, al subir de tono para que México detuviera ese flujo (Bolton, 2020; Woodward, 2020), hicieron que se detuvieran las visas humanitarias, en marzo y abril; c) el presidente Trump amenazó en mayo de 2019 con imponer aranceles comerciales si no se reducía el flujo migratorio y México se fue al polo opuesto.

México acordó, con el gobierno estadounidense, incrementar los controles en la frontera con Guatemala a partir de junio. Rápidamente redujo el flujo migratorio, afectó las rutas e incrementó los costos y riesgos de la migración indocumentada, como ya antes había ocurrido (Anguiano y Trejo, 2007). Esa política de contención migratoria, sin precedente, y por muy justificada que sea desde la lógica de vinculación económica, pareció tener poco tiempo para idear una solución distinta (Castañeda, 2019).

Trump ganó la partida a mediados de 2019. Detuvo el alud creciente de solicitudes de asilo y logró establecer fronteras migratorias escalonadas fuera del territorio estadounidense, con amenazas comerciales. De México logró: a) desde junio, se dispusieron 12 mil 500 elementos de la Guardia Nacional y 20 mil soldados en sus fronteras y lugares estratégicos, además del personal del Instituto Nacional de Migración (INM) para la contención migratoria, y b) se aceptó que 
en territorio mexicano aguardaran la resolución los extranjeros solicitantes de asilo en Estados Unidos (Meyer e Isacson, 2019). De Guatemala, que aceptara contener los flujos extranjeros que llegaban a su territorio con intención de ir a Estados Unidos. Adicionalmente, la Corte estadounidense autorizó que el presidente Trump usara 2 mil 500 millones de dólares para el muro. El presidente Trump también logró el cambio de criterios para el otorgamiento de asilo. En cifras, ese conjunto de disposiciones se traduce en lo siguiente: de 58 mil 317 migrantes indocumentados que detuvo Estados Unidos en su frontera sur, cuyo pico máximo fue de 144 mil 116 en mayo, en septiembre, la fecha convenida con México para que dereciera el flujo si no habría aranceles, el total de migrantes detenidos disminuyó a 52 mil 546. Es decir, se redujo significativamente el flujo. Trump logró su cometido, y México, ¿qué logró?

El gobierno mexicano celebró haber impedido las sanciones, y al término del semestre de 2020 México resultó el principal socio comercial de Estados Unidos. Con 90 millones de dólares y algunos otros patrocinios concertados con los gobiernos del norte centroamericano, junto con otra inversión para el Istmo, el malestar de esos gobiernos no pasaría a mayores (en la balanza comercial de México, Centroamérica representa apenas 1.3). Así, el gobierno de México conjugó acuerdos migratorios y comerciales con Estados Unidos y pensó palear los efectos con los gobiernos del norte centroamericano. Desde la prioridad del vínculo económico, el costo por la contención migratoria fue algo subsumible.

Que el presidente Trump pudiera ordenar nuevas expulsiones de mexicanos en Estados Unidos y proseguir sus ataques a la inmigración era algo que México no podía evitar. En ese caso, la lógica del gobierno mexicano sería la de sobrellevar la situación con la esperanza de que ese proceder fuera temporal y perdiera importancia con el resultado electoral final, a la vez que aguardaba que las reacciones internas fueran un freno a la intolerancia migratoria. La esperanza mexicana era que si el presidente Trump se reelegía el tema migratorio perdiera importancia política o siguiera el mismo cauce de la contención migratoria. Pero si ganaba el candidato demócrata, como sucedió, esperaría una actuación diferente de la Casa Blanca que modulara su aplicación a fin de marcar distancia de la administración precedente y mejorar el clima con México. En cualquiera de esas dos posibilidades, México se adecuaría a los nuevos tiempos con tal de fortalecer el vínculo comercial mediante el T-MEC y mantendría, quizá con un poco de menor rigor, la política de contención migratoria en curso. Con esas expectativas trabajaba el gobierno mexicano cuando llegó la covid-19. 


\section{Las prioridades, las prisas y los abusos}

2020 quedará como hito histórico mundial por la covid-19. Fueron varios los gobiernos en el mundo que optaron por cerrar sus fronteras nacionales a los migrantes internacionales como una medida preventiva. Aunque éste no es el lugar para evaluar las políticas gubernamentales contra la pandemia, es indudable que las actuaciones y percepciones de exclusión a la migración internacional han significado mayores costos en vida y riesgos diversos para quienes, independientemente del virus, tienen que emigrar de sus países dado que ahí las trayectorias estructurales y la conflictividad social se mantienen inalterables (Wolf, 2020).

La pandemia y sus efectos en las políticas migratorias es algo contextual en este análisis. Lo más significativo de lo ocurrido durante 2020 es la clara articulación entre migración internacional, salud, acuerdos económicos y reafirmación de pactos de seguridad nacional, con Estados Unidos como el principal beneficiado de dicha articulación. En este segmento presento elementos de valor estratégico para Estados Unidos, que significan prioridades, y para México la subordinación del tema migratorio a su prioridad de vinculación económica con su vecino del norte.

Las medidas de salud pública en Estados Unidos pasaron, a partir de febrero de 2020, por un triple filtro: seguridad, economía y migración (Woodward, 2020). La pandemia empezó a ser usada con el propósito de justificar medidas extremas, máxime que Estados Unidos había llegado a 2019 con más de un millón de casos pendientes de solución en las cortes de inmigración, con sólo 444 jueces para atenderlos (Cornelius, 2020), más lo acumulado en el año. Había que detener el flujo creciente en 2020. Las razones ideológicas le daban más peso a las objetivas y técnicas inmediatas.

A las medidas previas de contención migratoria se sumaron otras más que aplicaron de manera progresiva y en tiempo muy corto. Cabe resaltar la rapidez con que se procedió, a veces con diferencia de días, pero todo incuestionablemente con una clara directriz: contener el flujo migratorio, documentado o no, en tránsito o en el lugar de destino, solicitante de refugio o no. Para los migrantes extranjeros las medidas extraordinarias tomadas por la administración Trump afectan de forma inmediata su vulnerabilidad diaria. Invito a quien lea este texto a hacer un esfuerzo de relacionamiento de dichas medidas aplicadas en tiempo y espacio a fin de aquilatar su trascendencia inmediata en la vida de las personas migrantes involucradas y sus familias. 
De manera sucinta, éstas son algunas de las medidas generales más destacadas, en particular las aplicadas en la frontera con México. Obsérvese la articulación de seguridad-economía-migración en un tiempo relativamente corto:

1. «Se restringe el ingreso a personas de China, Irán, Europa, Reino Unido e Irlanda, con excepción de portadores de green card y sus parejas o dependientes» (O'Hare y Hardingham-Gill, 16 de marzo de 2020).

2. "Las embajadas estadounidenses suspenden otorgamiento de citas, visas u otro trámite migratorio hasta nuevo aviso (Infobae, 18 de marzo de 2020).

3. "Al cierre de fronteras, se incrementa la vigilancia y patrullaje en frontera sur con México» (El Financiero, 20 de marzo de 2020).

4. "Desde el 18 de marzo de 2020 se invoca la facultad otorgada por la Ley del Servicio de Salud Pública de 1944 o la Ley del Cirujano General (Surgeon General), autoridad del Servicio Militar de Salud, para: suspender temporalmente los trámites migratorios, el cruce fronterizo y la aplicación al derecho al asilo; se incremente la presencia de cuerpos armados en la frontera; y se aceleren las deportaciones, incluyendo las de niños, niñas y adolescentes no acompañados» (Hernández y Miroff, 3 de abril de 2020).

5. «Se impide la entrada de extranjeros que representen un riesgo para la salud pública» (U.S. Mission to Mexico, 4 de febrero de 2020).

6. «El Servicio de Inmigración y Control de Aduanas ajustó su spostura de aplicación de la leys en medio de la pandemia, afirmando que no llevará a cabo redadas o detenciones cerca de centros de salud, ssalvo en las circunstancias más extraordinarias». Sin embargo, las redadas y detenciones no cesan incluso en las regiones más afectadas por covid-19 como California y Nueva York» (Chishti y Pierce, 26 de marzo de 2020).

7. «El Servicio de Inmigración suspendió los servicios en persona, incluyendo todas las entrevistas y ceremonias de naturalización» (Álvarez, 19 de marzo de 2020).

8. «El Departamento de Justicia cerró 10 tribunales de inmigración hasta el 10 de abril y pospuso todas las audiencias de casos de inmigrantes no detenidos» (Jervis, 17 de marzo de 2020).

9. «Los tribunales exigirán a abogados llevar una máscara N95, de lo contrario no podrán entrar y los migrantes correrán el riesgo de no ser defendidos» (Jervis, 17 de marzo de 2020). 
10. «El presidente Trump emitió una orden ejecutiva para prohibir el otorgamiento de green cards. Frena así la migración legal» (Bash, 21 de abril).

11. «La Corte Suprema autorizó la deportación de residentes legales que hubiesen cometido delitos hasta siete años antes» (El Economista, 23 de abril de 2020).

12. «El Gobierno Federal puso en marcha el programa Covid-19 Emergency Bill Relief, por USD 2 billones de dólares. El programa no incluye ayuda a migrantes irregularizados o a familias mixtas donde uno de los miembros sea migrante irregularizado» (Snell, 26 de marzo de 2020).

13. "La Asociación de Fabricantes de Motores y Equipos (MEMA) envió una carta al secretario de Estado, Mike Pompeo, en la que le piden abogue para que las plantas de motores y autopartes en México reanuden operaciones el 12 de mayo» (El Universal, 6 de mayo de 2020).

México tomó disposiciones que también articulan aspectos de economía, seguridad estadounidense, salud y migración internacional. Aquí se presenta una selección de las principales medidas:

1. «Se estrecha la cooperación entre México y Estados Unidos en materia migratoria y control fronterizo durante la pandemia» (Infobae, 12 de marzo de 2020).

2. "Los albergues migratorios gubernamentales y civiles se encuentran al límite de su capacidad, un riesgo de contagio» (Reina, 21 de marzo de 2020).

3. "La Secretaría de Gobernación suspendió temporalmente plazos, términos y actividades para resolución de solicitud de refugio" (La Jornada, 24 de marzo de 2020).

4. "Ante la muerte de una persona extranjera durante una protesta en Tabasco, el INM declaró que actuó pacíficamente y responsabilizó a las personas que protestaron. Testimonios de personas indican que agentes de migración y de la Guardia Nacional les impidieron la salida del edificio en llamas» (Torliere, 1 de abril de 2020).

5. "Hay detenciones arbitrarias por policías y no por la autoridad migratoria» (Human Rights Watch, 14 de abril de 2020).

6. "A finales de abril se liberó a la casi totalidad de migrantes detenidos en las estaciones migratorias, la mayoría centroamericanos» (García, 26 de abril de 2020). 
7. "Las solicitudes de asilo se desplomaron en México 90 por ciento durante el mes de abril» (González, 18 de abril del 2020).

8. "La Confederación de Cámaras Industriales pidió al Gobierno Federal homologue con Estados Unidos y Canadá los sectores esenciales que tienen estipulados en México ante la parálisis de áreas productivas por el coronavirus» (Milenio, 22 de abril de 2020).

9. «En México el freno industrial en 11 estados afecta al Pentágono: 300 corporativos aeroespaciales estadunidenses tienen presencia en 11 estados de México, algunos de ellos con una relación directa con el Pentágono como Boeing, Gulfstream, Northrop Grumman, BAE Systems, Esterline de México, Precision Castparts Airfoils, Souriau, Cobham S.A. de C.V., Textron y Kaman y Hartwell» (Michel, 13 de mayo de 2020).

10. "Reanudaron labores fábricas y un bloque de armadoras que proveen a la industria militar estadunidense» (Reza y Barquet, 19 de mayo de 2020).

11. "La Comisión Mexicana de Ayuda a Refugiados continúa recibiendo solicitudes de refugio» (Ortiz, 27 de mayo de 2020).

12. "México ordena el cierre de su frontera sur y redobla la vigilancia fronteriza» (Rea, 3 de junio de 2020).

13. «27,000 miembros de las fuerzas armadas son desplazados a las fronteras norte y sur» (Rea, 3 de junio de 2020).

14. Bajo el programa "Remain in Mexico», el gobierno mexicano acordó con Estados Unidos: a) aceptar a mexicanos devueltos y a centroamericanos que quedarían varados en la frontera norte hasta que reactiven procesos migratorios; b) atender a miles de centroamericanos y proveer apoyos a albergues en la franja fronteriza o en campos de refugiados; c) brindar apoyo a mexicanos deportados para que retornen a sus comunidades de origen vía terrestre y a quienes se realicen pruebas de contagio e identificación de casos de covid-19 a la llegada; d) recibir a niños, niñas y adolescentes (NNA) mayoritariamente centroamericanos deportados desde Estados Unidos o que quedaron varados por cierre fronterizo, y darles atención prioritaria ubicándolos en estaciones migratorias.

15. "Migración mexicana suspende temporalmente la ampliación de permisos de estancia para continuar en el país: la medida produce irregularidad migratoria y exacerba deportación» (Rea, 4 de junio de 2020).

16. "ACNUR México suspende temporalmente programa de reubicación» (ACNUR, 4 de junio de 2020). 
17. "Las 32 estaciones migratorias y 26 estancias provisionales presentan hacinamiento» (El Universal, 14 de junio de 2019).

18. «El 1 de julio entró en vigor el Tratado entre México, Estados Unidos y Canadá, T-MEC» (Expansión, 1 de julio).

19. "El mayor consumo en Estados Unidos reanima a las exportaciones mexicanas. Los estadounidenses elevan su consumo gracias a los estímulos emitidos en ese país» (Expansión, 11 de agosto de 2020).

20. "La situación económica y la reapertura comercial en Estados Unidos favorecen la recuperación de México» (Castañares, 19 de agosto de 2020).

21. "Las remesas a México crecieron en julio por tercer mes consecutivo» (Forbes, 1 de septiembre de 2020). El monto acumulado para el primer semestre superaba los 20 mil millones de dólares americanos.

22. "Durante enero-julio, México fue el principal socio comercial de Estados Unidos en el mundo. El valor de las exportaciones mexicanas al mercado estadounidense ascendió a 173 mil 144 millones de dólares, mientras que las importaciones sumaron 117 mil 483 millones de dólares» (El Universal, 3 de septiembre de 2020; The U.S. Department of State's Investment Climate Statements, 2020).

23. "Parte de los recursos de un fondo de cooperación y desarrollo para Centroamérica fueron utilizados por México para deportar a inmigrantes centroamericanos indocumentados, expulsados de Estados Unidos» (The Associated Press, 8 de septiembre de 2020).

Las medidas de contención migratoria de los gobiernos de Estados Unidos y México, con y sin la covid-19, lograron reducir de manera significativa la migración internacional indocumentada. Ése era el propósito y lo lograron; la pandemia facilitó las cosas. También es un hecho que la vinculación económica da sus mejores frutos en tanto que México fue el principal socio comercial de Estados Unidos en el primer semestre de 2020. La otra cara de la moneda es que las políticas de contención migratoria de 2019 y 2020 ponen en duda la vigencia de tres derechos de las personas: a) solicitar asilo en caso de persecución; b) no ser devuelta a donde corra peligro de persecución; c) ser protegida en contra de la tortura. A la vez se ponen en entredicho: a) las garantías básicas del derecho al debido proceso y b) las garantías y protecciones legales para niños migrantes no acompañados (Ortega, 2020a; 2020b). Desde la realpolitik con la que ambos gobiernos actúan, esas preocupaciones parecieran no ser de su incumbencia, o 
no ser el momento de atenderlas. La relación entre esos dos poderes siguió su buen curso.

\section{Las articulaciones estructurales y los equívocos}

Es legítimo tener un proyecto de nación e impulsarlo desde el gobierno. Pero, en algún momento, hay que verificar si lo que se negocia y cómo se negocia es lo mejor para el país y el proyecto. Por lo antes dicho, hay algunas articulaciones temáticas producto de la vecindad, lo cual es entendible, pero hay valoraciones y actuaciones sujetas a escrutinio mayor, sobre todo cuando los costos causan mayores desequilibrios o resultan inaceptables. Hay equívocos de México que tiene que dejar atrás si quiere fortalecer su vínculo económico sin sobrecostos en seguridad y migración.

Equívoco uno: al hacer concesiones de cualquier índole mejora su relación comercial con Estados Unidos. Diferir en concepción, en qué y cómo hacer no es sinónimo de conflicto, como negociar no es hacer concesiones, sino convenir intercambios. Las cartas poseen doble valor: el que le da quien las tiene en la mano y el que le da la contraparte. Usar en beneficio propio el sobrevalor que la contraparte otorga a tus cartas, a las que tú les puedes asignar un subvalor, te da una ventaja inigualable. Importa en especial no permitir que la contraparte conozca el subvalor que tú le das a algunas de tus cartas.

Tomar el valor relativo de las cartas propias y evitar mostrar sus valores diferenciados es elemental en una mesa de negociación política. En la negociación es un error hacer concesiones gratuitas. México le dio un sobrevalor a la carta economía y un subvalor a las cartas migración y seguridad, Estados Unidos supo de esos valores relativos y lo aprovechó, como ya se dijo. Se puede contraargumentar que México aceptó unas reglas del juego y es obligatorio respetarlas. No es así. Las reglas se ajustan al paso del tiempo. Estados Unidos ha cambiado y cambia las reglas según le convenga. Con el presidente Trump el reacomodo de acuerdos fue la constante (Bolton, 2020; Comey, 2018; Wolf, 2018). Es posible entonces establecer un nuevo acuerdo. No es fácil: quien innova y cuenta con relativamente menos fuerza tiene que ser más ingenioso y perseverante con el objeto de jugar mejor sus cartas.

Segundo equívoco: en lo migratorio no pedir al Norte (Estados Unidos) lo que no se haga en el Sur (Centroamérica) porque se pierde fuerza moral. En 
principio, esa propuesta de congruencia está en el discurso mexicano y no en el de Estados Unidos, quien nunca ha planteado tal cosa para tratar mejor al inmigrante mexicano. Por otro lado, la incongruencia en políticas determinadas no es obstáculo para avanzar y lograr acuerdos entre países (Clinton, 2016; Castañeda, 2020). México no debe plantearse problemas de moral que nadie le exige resolver antes de hacer algo: es más un argumento que justifica el inmovilismo que la acción positiva.

La responsabilidad compartida entre países involucrados es la mejor opción. La acción multilateral no sustituye, sino que complementa, las políticas locales y bilaterales. Lo dicho por el presidente Trump en su discurso el 23 de septiembre de 2020 en la ONU, en el que hizo referencia a las «históricas alianzas» que había alcanzado con México, Guatemala, Honduras y El Salvador concernientes a la contención de la inmigración a Estados Unidos, es buen ejemplo de ello, aunque Trump lo diga para uso unilateral y no regional. ${ }^{7}$ La política gubernamental es una construcción sustentada en ideas, recursos materiales y capacidad de gestión de acuerdos con distintos actores en distinto tiempo y modalidad. La realidad inmediata muestra que las acciones unilaterales de expulsión siguen en marcha y los países de origen y tránsito pagan costos más altos sin que el acuerdo multilateral se logre, menos cuando se exacerba la política migratoria wasp y altamente selectiva. Estados Unidos sabe que puede lograr lo que quiere a bajo costo o sin costo alguno. En estos meses de pandemia, no sólo las grandes potencias están modificando sus políticas migratorias y Estados Unidos está teniendo que adecuarse, como se ejemplificará enseguida.

Tercer equívoco: se dice que México es un país de exitosa tradición de asilo y refugio. En distintos momentos han llegado al país distintas comunidades extranjeras que tienen en común ser clase medio, culta, no muy numerosa y acotada en el tiempo. Sin embargo, sólo son dos los momentos estelares: el refugio español y el asilo a los perseguidos políticos del Cono Sur de finales de los 1970 y principios de los 1980. Caso excepcional fue el de los miles de guatemaltecos, pobres y analfabetas, que llegaron de súbito y sorpresivamente. Fue obligada su

\footnotetext{
${ }^{7}$ Dos son las razones para tal reconocimiento: la de mayor data, el flujo migratorio que de manera indocumentada pretende llegar a Estados Unidos en volumen acrecentado. En enero de 2019 Estados Unidos detuvo 58 mil 317 migrantes indocumentados en su frontera sur y en junio 144 mil 116, y se preveía una ola migratoria mayor; la circunstancial, la aparición de la covid-19, que en el caso estadounidense llevó a vincular el tema de la migración con las medidas de prevención sanitaria y la seguridad nacional (Woodward, 2020).
} 
atención. Lejos de reconocimiento está lo ocurrido con los chinos explotados y muchos asesinados en los 1930, los mineros bolivianos, haitianos y los centroamericanos de los últimos 50 años, además de los africanos del último decenio. Todos ellos han tenido en común ser gente pobre, del campo, analfabeta casi toda, y en el caso de los procedentes del norte centroamericano o de Cuba, en un fluir constante. En 2017 y 2018, y a pesar de que el mayor número de solicitudes de refugio provino de hondureños (clase baja y con escasa calificación), hubo más aceptación de venezolanos (clase media, con estudios, calificación y recursos financieros). Estos hechos muestran dónde están las preferencias de México y dónde no.

\section{Reflexiones y propuesta}

En mayo y junio de 2019 fue difundida ampliamente la idea de que el gobierno del presidente mexicano se vio obligado a ordenar la contención migratoria a fin de evitar los aranceles que enunció el presidente estadounidense. Una acción obligada que detuvo represalias. Así dicho, es un argumento de fácil divulgación que evita sea relacionado con la prioridad económica mexicana y la prioridad estadounidense de la seguridad. La amenaza de los aranceles se puede presentar en cualquier otro momento. México debe evitar que esa eventualidad se presente y no lo va a lograr haciendo más concesiones en materia de seguridad y migración. Incluso, hasta lo económico resulta inviable. El futuro no es unívoco. Se puede modificar si se sabe qué hacer y por qué hacerlo.

¿Cómo negociar con una potencia que es tu vecina y con la cual quieres integrar tu economía? Teniendo varios temas en la agenda binacional, cómo procedes, ¿los gestionas de manera independiente o los integras en un paquete? Ésta es una pregunta recurrente en México, al menos en el siglo XX, desde 1970, cuando la crisis del petróleo, de 1990 cuando se negociaba el TLCAN, y reiterada en 2018 con el T-MEC. En los hechos, México ha procurado subordinar, sea en paquete o por separado, los distintos temas a la prioridad máxima: la vinculación económica y eso, a mi parecer, lo ha puesto en una situación de desventaja en todo momento. Veámoslo desde la óptica de la migración.

Hay que valorar y jugar distinto las tres cartas constantes en el vínculo con Estados Unidos. Cada una posee diferente valor para cada una de las partes. Ello a partir de una situación de asimetría en la relación migratoria y del valor dado 
a la carta migratoria para establecer nuevos términos. Ir hacia la simetría en la relación migratoria, asociada con los otros dos temas, es el punto de partida para construir una vecindad menos desequilibrada entre ambos países.

Los temas migratorios no han sido de interés para México, pero sí un vínculo obligado con Estados Unidos. México cuenta con 67 consulados en el mundo y 50 de ellos están en ese país. El resto del mundo no tiene la misma relevancia, no obstante que más de 50 nacionalidades distintas transitan de manera indocumentada por el país y otras tantas engrosan los flujos documentados. La migración, en tanto que no ha sido ni es considerada trascendente por y para México, podría ser una carta de negociación a favor y no una carta en contra o de menor valor, como ha sido hasta ahora. La poca importancia que México le dio al tema migratorio llevó a asignarle un subvalor en la negociación con Estados Unidos. La contraparte logró más de lo que quería a un costo bajo o ridículo. Esto es lo primero que hay que cambiar: la percepción acerca del valor que entraña la carta migración para México, tanto en sus relaciones externas como en su proceso poblacional interno, en el entendido de que se trata de la migración en tránsito.

Ser una potencia mundial implica costos, no sólo beneficios. Estados Unidos está en su derecho de usar sus cartas como mejor le parezca para la defensa y acrecentamiento de sus intereses. Al respecto, sus intereses no son los de México, ni México es parte de Estados Unidos. En toda relación bilateral hay costos y beneficios y si Estados Unidos quiere fortalecer su seguridad debe pagar por ello. México ha cometido errores estratégicos al subvalorar su carta migratoria y su acción práctica a la seguridad estadounidense en aras de su relación comercial. Ciertamente se ha incrementado el intercambio comercial, pero hay tres efectos contrarios que no niegan la «exitosa» sociedad del momento, pues la economía mexicana es altamente dependiente de los vaivenes de la economía de Estados Unidos. México no está lejos de ser un país maquilador de la economía estadounidense:8 1. Sus actividades más dinámicas de la economía nacional dependen en exclusiva de la estadounidense, algo construido a lo largo de decenios.

\footnotetext{
${ }^{8}$ Se estima que la población que labora en la industria maquiladora en los seis estados fronterizos de México asciende a más de 1.6 millones de personas, distribuidas entre más de 3 mil establecimientos. A ello hay que agregar las otras industrias en otros cinco estados más. Es decir, 11 estados, un tercio del total del país, tienen sus actividades económicas más productivas vinculadas a la economía estadounidense. Del total de entidades federales, esas 11 destacan por ser las que más contribuyen al PIB nacional.
} 
2. Los vínculos comerciales mexicanos con Estados Unidos son susceptibles de ser usados en su contra (como de modo grotesco lo ha hecho el presidente Trump, pero otros antes que él también lo han hecho, quizá con guante blanco). 3. La mejora de la economía estadounidense no impulsa mecánicamente a la economía mexicana, o si lo hace es sólo en las actividades vinculadas o dependientes de la economía estadounidense. Mal negocio para México: en lo económico crece en dependencia y vulnerabilidad más allá de algunos activos comerciales y su actuación en migración y salud por la pandemia van acordes a la seguridad estadounidense con costos objetivos y subjetivos sin beneficio verificable. México ha jugado mal sus cartas, solas y combinadas. No tiene forzosamente que seguir con ese juego desequilibrado en su contra. Tampoco puede levantarse de la mesa. Es preciso que juegue de forma distinta sus cartas, solas y combinadas. Cómo jugar las cartas también tiene que cambiar.

Los temas de migración y seguridad se han mezclado. Se seguirán mezclando lo quiera México o no: lo rebasan la seguridad estadounidense y la migración centroamericana. México puede modificar esa mezcla, por la parte más onerosa, con el propósito de evitar los sobrecostos que paga al estar en el centro de ese «sanguis». Estados Unidos no tiene reciprocidad migratoria: el mexicano debe pagar por una visa si quiere entrar a Estados Unidos y el estadounidense entra a México sólo con su pasaporte. Esa ausencia de reciprocidad es una de las primeras cosas que se deberían corregir.

Estados Unidos cobra el trámite de visa a todos los nacionales de los países según lo establece su clasificación del mundo (160 dólares). Los mexicanos pagan el trámite como muchos otros. Empero, a diferencia de los demás, México ha hecho adecuaciones institucionales, administrativas y de actuación de sus autoridades de migración y de seguridad acordes con el interés superior de la seguridad estadounidense, en concreto en sus instancias de migración y aduanas. Esa diferencia es lo que marca un valor diferente a las cartas migración y seguridad en la relación entre ambos países. El temor mexicano de cobrar a los estadounidenses por la visa es que se afecte el turismo del que tanto recibe y más se espera. Otra vez se mezclan peras con manzanas. Si los estadounidenses que desean ingresar a México pagan por la visa correspondiente, no hay pérdida segura de ingresos por una posible baja circunstancial en el turismo y podrá haber una mejora en los términos de la gestión si hay reciprocidad migratoria en este otro rubro. El respeto se logra con el buen manejo de las cartas, con la astucia para avanzar y no con procederes timoratos, máxime si se enfrenta a un contrincante con más fortalezas 
desarrolladas. El David tiene que aquilatar las debilidades del Goliat y aprovecharlas.

Brasil ha logrado reciprocidad y el turismo estadounidense sigue al alza, y eso que Brasil está a miles de kilómetros de la frontera sur estadounidense. El turismo estadounidense seguirá visitando México: es imprescindible hacer valer la cercanía y el tipo de cambio. Una visa no es un impedimento. Es un cambio indispensable que debe realizarse como ya lo hacen otros países en el mundo. A raíz de la pandemia de la covid-19 los estadounidenses han tenido que tramitar visas en países en los que antes no la requerían. El 12 de septiembre de 2020 un viajero con pasaporte estadounidense podía ingresar sin visa a 87 países, mientras un año atrás ese mismo pasajero podía hacerlo a 171 países (Velásquez, 2020).

Cobrar por el otorgamiento de visa a los estadounidenses se justifica cabalmente. Hay sólidas razones prácticas e inmediatas, aparte de las de fondo asociadas con la reciprocidad. Se necesita hacer erogaciones extraordinarias por la presencia de miles de extranjeros en distinta espera jurídica estadounidense en suelo mexicano, con diferentes implicaciones en la vida social nacional e internacional. El cobro de visa a estadounidenses se podrían usar para: 1. Fortalecimiento institucional y actuación de la autoridad migratoria mexicana. 2. Sufragar gastos de atención a la migración extranjera indocumentada. 3. Apoyo a los programas de empleo y mejora en el sureste mexicano, que incluyen a poblaciones extranjeras. 4. Programas de promoción internacional al turismo en México. 5. Apoyo a los programas de empleo y mejora en los lugares de origen de la migración en Centroamérica. 6. Gastos de infraestructura, personal y equipo del aparato gubernamental encargado de la gestión de visas. Es posible que los recursos sean insuficientes, pero es fundamental que tales acciones se lleven a cabo acorde con los planteamientos del gobierno actual. El pago de visa se podría hacer en alguno de los 123 puestos fronterizos (42 aéreos, 40 marítimos y 41 terrestres) o en alguno de los 50 consulados mexicanos en Estados Unidos.

Dos serían las posibles reacciones en contra de esa medida: 1. Interna, de quienes les preocupa la reducción del turismo y la cancillería, en particular porque su titular no es partícipe de abordar temas que incomoden al gobierno de Estados Unidos y porque, de hacerse la actividad, implicaría mayor trabajo para los consulados mexicanos en Estados Unidos. 2. Externa, la del presidente Trump, pues los demócratas y sus críticos le responsabilizarían de esa medida que afectaría a los electores estadounidenses. No es descartable que, en ese escenario, el presidente Trump acelerara la expulsión masiva e indiscriminada de migrantes mexicanos 
en Estados Unidos, aunque es muy poco factible en el poco tiempo que le queda y porque el gobierno mexicano ha sido muy cauto en el manejo de tiempo para expresar la felicitación al candidato ganador, el demócrata Joe Biden. Por lo expresado y reiterado por el presidente López Obrador, su gobierno no correría el riesgo de tomar una iniciativa que causara discrepancia al gobierno estadounidense, no obstante, cabe señalar que algunos de sus antecesores sí han discrepado en temas internacionales de las posiciones estadounidenses. Tales fueron los casos de los entonces presidentes José López Portillo y la declaración franco mexicana sobre El Salvador, Miguel de la Madrid con el Grupo Contadora, Carlos Salinas de Gortari, quien condenó la invasión de Panamá (los tres en tiempos de la todavía Guerra Fría y la atención en Centroamérica por parte de Estados Unidos era de celo extremo, Powell y Persico, 1995) y Ernesto Zedillo que, pese a la amenaza de moratoria, logró el apoyo de W. Clinton.

Por lo expresado y reiterado por el presidente mexicano, su gobierno no correría el riesgo de tomar una iniciativa que causara discrepancia con el gobierno estadounidense. Cobrar por la visa a los estadounidenses, por muy deseable y factible que sea, no es políticamente viable por el momento. La pregunta que queda entonces es: ¿de dónde saldrán los ingentes recursos financieros para atender todas las afectaciones sociales, económicas y de gobernabilidad que se presentan y más se presentarán en el futuro inmediato con los miles de extranjeros «estacionados» en México de manera forzosa mientras Estados Unidos decide si les otorga o no el asilo solicitado? Seguramente del mermado erario mexicano. La otra pregunta, más complicada: ¿se mantendrá la política migratoria subordinada a Estados Unidos y con altos y lamentables costos que, tarde que temprano, también mermen la viabilidad de la prioridad económica mexicana?

La ausencia de reciprocidad se expresa en un conjunto de acciones de diverso tipo que ocurren todos los días y no se limita sólo a las visas. La agenda migratoria estadounidense forzosamente se subordina a temas de seguridad, que no es el caso de México, y ve en la migración internacional peligros, que tampoco es el caso de México: la infiltración terrorista (que es compartida por republicanos y demócratas) y el fin del mestizaje wasp (preocupación más republicana que demócrata). Sin seguridad no hay comercio seguro, por eso el comercio, aparte de los beneficios que en sí significa, también es un medio para obtener la seguridad que se desea. Así lo ha mostrado el presidente Trump.

México, en tiempo real, proporciona a Estados Unidos toda la información migratoria que capta (incluyendo la biométrica) de todos los solicitantes de visa, 
de todos los extranjeros documentados que de México parten rumbo a Estados Unidos, o que harán escala en ese país, y de todos los indocumentados detenidos que transitan por el territorio mexicano con la intención de cruzar la frontera norte. ${ }^{9}$ México tiene el derecho de contar con la información correspondiente de su contraparte, pero, ¿para qué la necesita si no tiene problemas de seguridad nacional como sí la tiene Estados Unidos? Estados Unidos es el único país beneficiado con ese acuerdo. Miles de datos migratorios al día, casi gratis. Ese hecho es una muestra fehaciente del sobrevalor de la carta seguridad para Estados Unidos, del subvalor de la carta migración para México y el suponer mexicano de que tales concesiones favorecen el clima general que beneficia su interés en lo económico, un supuesto no comprobado. A cambio de unos peanuts e ilusiones México ha cuidado la frontera sur de Estados Unidos durante decenios y de manera creciente desde 2001 y 2019. ¿Se seguirá por esa ruta de mayor subordinación o se buscará renegociar la colaboración entre países vecinos?

Para México la vinculación económica y comercial con Estados Unidos sigue siendo la prioridad más alta. La puede seguir teniendo, pero no hay garantía de lograrla sin mayores costos y más afectación de su decoro. El vínculo con Estados Unidos es importante (Castañeda, 2020), sin embargo, el mundo ofrece más si se le sabe ver (Frankopan, 2015; Hughes, 2017).

Los migrantes internacionales pagan los costos personales, más con la pandemia. Ellos no forman parte de las prioridades del gobierno de destino, no de las del de tránsito, tampoco de los gobiernos de los países de origen. Se tienen a sí mismos, a sus familias, a sus redes de apoyo y algunos sectores sociales en los lugares de origen, tránsito y destino migratorio. No está mal, pero su circunstancia podría ser mejor, podría cuando sean conceptualizados y tratados como parte activa de la sociedad y no sólo un componente de ese miedo líquido de la sociedad occidental actual (Bauman, 2007). La materia de cambio son las cartas, revaloradas, no las personas migrantes.

\footnotetext{
${ }^{9}$ Esos registros tan amplios y actualizados se deben a que México cuenta con el Sistema Integrado de Operación Migratoria (SIOM), que en buena parte se creó y funciona gracias al patrocinio parcial de Estados Unidos, quien también dio la capacitación, desde inicios del siglo XXI. Luego México lo compartió con Guatemala. Son los únicos países que tienen sistemas similares y comparables en toda América Latina (OIM, 2012) y ambos comparten su información con Estados Unidos.
} 


\section{Referencias}

Agencia de la ONU para Refugiados (ACNUR) (4 de junio de 2020). "ACNUR suspende temporalmente el Programa de Integración Laboral». Recuperado de https://help. unhcr.org/mexico/2020/06/04/acnur-suspende-temporalmente-el-programa -de-integracion-laboral/

Álvarez, P. (19 de marzo de 2020). «12 cambios en el sistema de inmigración de EE.UU. durante la pandemia de coronavirus». CNN. Recuperado de https://cnnespanol.cnn. com/2020/03/19/12-cambios-en-el-sistema-de-inmigracion-de-ee-uu-durante-la -pandemia-de-coronavirus/

Amnistía Internacional (2018). Ignoradas y sin protección: la mortal devolución de personas centroamericanas solicitantes de asilo desde México. Reino Unido: Amnistía Internacional.

Anguiano, M.E. y Trejo Peña, A. (julio-diciembre, 2007). «Políticas de seguridad fronteriza y nuevas rutas de movilidad de migrantes mexicanos y guatemaltecos». Liminar. Estudios Sociales y Humanísticos, v(2), pp. 47-65.

Bauman, Z. (2007). Miedo líquido. La sociedad contemporánea y sus temores. Barcelona: Paidós. Bolton, J. (2020). The room where it happened. A White House memoir. Nueva York: Simon \& Schuster.

Camus Bergareche, M., Vega Villaseñor, H. y Martínez Hernández Mejía, I. (2020). "Tensiones en la gestión de las caravanas migrantes por Guadalajara». EntreDiversidades: Revista de Ciencias Sociales y Humanidades, 7(1), pp. 62-91. DOI: https://doi. org/10.31644/ED.V7.N1.2020.A03

Casillas, R. (2020). Cronología migratoria. Recuperado de rodolfocasillasr.org

Chávez, K.R. (2019). «Understanding migrant caravans from the place of place privilege». Departures in Critical Qualitative Research, 8(1), pp. 9-16. DOI: https://doi. org/10.1525/dcqr.2019.8.1.9

Canales, A.I. y Rojas Wiesner, M.L. (2018). Panorama de la migración internacional en México y Centroamérica. Santiago de Chile: Cepal. Recuperado de https://repositorio. cepal.org/bitstream/handle/11362/43 697/1/S1800554_es.pdf

Canales, A., Fuentes Knight, J.A. y Escribano, C.R. (2019). Desarrollo y migración. Desafíos y oportunidades en los países del norte de Centroamérica. Comisión Económica para América Latina y el Caribe/Organización de las Naciones Unidas para la Alimentación y la Agricultura.

Castañares, G. (19 de agosto de 2020). «Sustenta economía de EU el repunte de México». El Financiero. Recuperado de https://www.elfinanciero.com.mx/economia/sustenta -economia-de-eu-el-repunte-de-mexico/ 
Castañeda, J. (2020). Estados Unidos: en la intimidad y a la distancia. México: Debate.

Castañeda, J. (2019). «¿México será su propio muro?» Nexos, XLI(500), pp. 33-39.

Chishti, M. y Pierce, S. (26 de marzo de 2020). "Crisis within a crisis: immigration in the United States in a time of COVID-19». Migration Information Source. Recuperado de https://wWw.migrationpolicy.org/article/crisis-within-crisis-immigration-time -covid-19

Clinton, H. (2015). Hard Choises. Estados Unidos: Simon \& Schuster.

Comey, J. (2018). A higher loyalty. Truth, lies, and leadership. Estados Unidos: Macmillan.

Cornelius, W. (2020). La política de inmigración de la administración Trump: realidades, contradicciones y perspectivas. México: Centro de Investigación y Docencia Económicas.

De la Rosa, E. (22 de abril de 2020). "Urge que México iguale a sectores esenciales con EU y Canadá: Concamin». Milenio. Recuperado de https://www.milenio.com/ negocios/coronavirus-concamin-pide-mexico-iguale-sectores-eu-canada

El Economista (23 de abril de 2020). "Corte Suprema de EU facilita deportar a inmigrantes que hayan cometido crímenes». Recuperado de https://www.eleconomista.com. $\mathrm{mx} /$ internacionales/Corte-Suprema-de-Estados-Unidos-facilita-deportar-a-inmigrantes-que-hayan-cometido-crimenes-20200423-0110.html

El Financiero (20 de marzo de 2020). «EU iniciará deportación inmediata de migrantes por COVID-19». Recuperado de https://www.elfinanciero.com.mx/mundo/eu-iniciara -deportacion-inmediata-de-migrantes-por-covid-19/

El Universal (6 de mayo de 2020). "Industria automotriz en EU pide abrir plantas en México el 12 de mayo». Recuperado de https://www.eluniversal.com.mx/cartera/ industria-automotriz-en-eu-pide-abrir-plantas-en-mexico-el-12-de-mayo

El Universal (3 de septiembre de 2020). "México recupera «la corona» como principal socio comercial de EU». Recuperado de https://www.elfinanciero.com.mx/economia/ mexico-recupera-la-corona-como-principal-socio-comercial-de-eu/

Expansión (1 de julio de 2020). «El T-MEC entra en vigor. Esto es todo lo que debes saber». Recuperado de https://expansion.mx/economia/2020/07/01/el-t-mec-entra-en -vigor-esto-es-todo-lo-que-debes-saber

Expansión (11 de agosto de 2020). "El mayor consumo en Estados Unidos reanima a las exportaciones mexicanas». Recuperado de https://expansion.mx/economia/2020 /08/11/consumo-estados-unidos-reanima-exportaciones-mexicanas

Frankopan, P. (2015). The silk roads. Estados Unidos: Crítica.

Forbes (1 de septiembre de 2020). "Remesas a México «vuelven a sorprender: crecen por tercer mes consecutivo». Recuperado de https://www.forbes.com.mx/economia-remesas -a-mexico-vuelven-a-sorprender-crecen-por-tercer-mes-consecutivo/ 
García, C. (26 de abril de 2020). "Cierran estación migratoria Tenosique tras muerte de migrante». El Universal. Recuperado de https://www.eluniversal.com.mx/nacion/ cierran-temporalmente-estacion-migratoria-tenosique-tras-muerte-de-migrante

González, I. (18 de abril del 2020). «Disminuyen 90\% solicitudes de refugio en abril». Reforma. Recuperado de https://www.reforma.com/aplicacioneslibre/preacceso/ articulo/default.aspx?__rval=1\&urlredirect=https://www.reforma.com/dis minuyen-90-solicitudes-de-refugio-en-abril/ar1930077? referer =--7d616165662f3a3 a6262623b727a7a7279703b767a783a--

Gutiérrez, Ó. y Villa y Caña, P. (14 de junio de 2020). «Suman 21 migrantes muertos en estaciones». El Universal. Recuperado de https://www.eluniversal.com.mx/nacion /sociedad/suman-21-migrantes-muertos-en-estaciones

Guttentag, L. (13 de abril de 2020). "Coronavirus border expulsions: CDC's assault on asylum seekers and unaccompanied minors». Just Security. Recuperado de https://www. justsecurity.org/69640/coronavirus-border-expulsions-cdcs-assault-on-asylumseekers-and-unaccompanied-minors/

Hernández, A. (septiembre-octubre, 2020). «La frontera México-Estados Unidos: asimetrías y transgresiones». Nueva Sociedad (289).

Hernández, A. y Miroff, N. (4 de febrero de 2020). «Mission to Mexico». Washington Post. Hughes, B. (2017). Istambul. A tale or three cities. Reino Unido: Da Capo Press.

Human Rights Watch (2019). We can't help you here: US returns of asylum seekers to Mexico. Nueva York: Human Rights Watch.

Human Rights Watch (14 de abril de 2020). «México debe liberar a los migrantes detenidos en el contexto de la pandemia». Recuperado de https://www.hrw.org/es/news /2020/04/14/mexico-debe-liberar-los-migrantes-detenidos-en-el-contexto-de-la -pandemia

Infobae (12 de marzo de 2020). «Redacción». Recuperado de https://www.infobae.com/ america/mexico/2020/03/12/eeuu-no-ve-conveniente-abrir-completamente-frontera -con-mexico-por-coronavirus/

Infobae (18 de marzo de 2020). «Estados Unidos suspendió el servicio de otorgamiento de visas en todo el mundo por el coronavirus». Recuperado de https://www.infobae. com/america/eeuu/2020/03/19/estados-unidos-suspendio-el-servicio-de-otorga miento-de-visas-en-todo-el-mundo-por-el-coronavirus/

Instituto Nacional de Estadística y Geografía (INEGI) (2015). Encuesta Intercensal. MéxiCO: INEGI.

Instituto Nacional de Migración (1996). Compilación histórica de la legislación migratoria en México 1909-1996. México: Talleres Gráficos de México. 
Isacson, A. (6 de abril de 2020). "The Trump administration's COVID-19 response at the border puts us all at risk». Washington Office on Latin America. Recuperado de https://www.wola.org/analysis/trump-covid19-response-at-border/

Jervis, R. (17 de marzo de 2020). «Migrants waiting at US-Mexico border at risk of coronavirus, health experts warn». USA Today. Recuperado de https:/www.usatoday.com/ story/news/nation/2020/03/17/us-border-could-hit-hard-coronavirus-migrants -wait-mexico/5062446002/

La Jornada (24 de marzo de 2020). "Anuncia Segob suspensión en diversos trámites por Covid-19». Recuperado de https://www.jornada.com.mx/ultimas/politica/2020 /03/24/anuncia-segob-suspension-en-diversos-tramites-por-covid-19-1964.html

Lemus, J. (9 de septiembre de 2020). «Tapachula: la «ercera República), donde el Covid-19, la violencia y la pobreza laceran a los migrantes». Los Ángeles Times. Recuperado de https:// www.latimes.com/espanol/mexico/articulo/2020-09-09/tapachula-la-tercera -republica-donde-el-covid-19-la-violencia-y-la-pobreza-laceran-a-los-migrantes

López Recinos, V. (2013). «Desarrollo, migración y seguridad: el caso de la migración hondureña hacia Estados Unidos». Migración y Desarrollo, 7(12).

Martínez, F. (24 de marzo de 2020). «Anuncia Segob suspensión en diversos trámites por covid-19». La Jornada. Recuperado de https://www.jornada.com.mx/ultimas/ politica/2020/03/24/anuncia-segob-suspension-en-diversos-tramites-por-covid -19-1964.html

Martínez, Ó. (2012). Los migrantes que no importan. Oaxaca: Sur+Ediciones.

Meyer, M. e Isacson, A. (2009). "The 'wall before the wall: Mexico's crackdown on migration at its southern border». Washington Office on Latin America.

Michel, P. (20 de marzo de 2020). "Quién sí y quién no podrá cruzar la frontera con EEUU». Telemundo. Recuperado de https://www.telemundo20.com/noticias/mexico/quien -si-y-quien-no-podra-cruzar-la-frontera/2001859/

Michel, V.H. (13 de mayo de 2020). «En México, freno industrial de 11 estados impacta al Pentágono». Milenio. Recuperado de https://www.milenio.com/negocios/ coronavirus-freno-industrial-mexico-afecta-pentagono

O'Hare, M. y Hardingham-Gill, T. (16 de marzo de 2020). "Lista de países que tienen prohibiciones de viaje de llegada en vuelos extranjeros por coronavirus». CNN. Recuperado de https://cnnespanol.cnn.com/2020/03/16/coronavirus-que-paises-tienen -prohibiciones-de-viaje-llegada-vuelos-extranjeros-lista/

Organización Internacional para las Migraciones (OIM) (2012). Evaluación rápida de las estructuras de recolección de datos en el área de las migraciones en América Latina y los países de Caribe. Organización Internacional para las Migraciones/Oficina Regional para el 
Espacio Económico Europeo/Unión Europea/Organización del Tratado del Atlántico Norte.

Ortega, Elisa (2020a). ¿México como tercer país (in)seguro? El asilo como derecho humano en disputa. México: Instituto de Investigaciones Jurídicas-Universidad Nacional Autónoma de México.

Ortega, Elisa (2020b). «Vidas desechables: deportación de migrantes irregulares, solicitantes de asilo y niños no acompañados de Estados Unidos por covid-19». Nexos.

Ortiz, A. (27 de mayo de 2020). "Comar dejará de resolver solicitudes de refugio por Covid-19». El Universal. Recuperado de https://www.eluniversal.com.mx/nacion/ sociedad/comar-suspende-solicitudes-de-refugio-por-covid-19

París Pombo, M.D. (coord.) (2018). Informe sobre los migrantes haitianos y centroamericanos en Tijuana, Baja California, 2016-2017. Politicas gubernamentales y acciones de la sociedad civil. Tijuana: El Colegio de la Frontera Norte/Comisión Nacional de los Derechos Humanos.

Pew Research Center (2017). Rise in U.S. immigrants from El Salvador, Guatemala and Honduras outpaces growth from elsewhere. Lawful and unauthorized immigrants increase since recession. Estados Unidos: Pew Research Center.

Powell, C. y Persico, J.E. (1995). My American Journey. Estados Unidos: The Random House.

Rea, D. (3 de junio de 2020). «Hipernacionalismo, cierre de fronteras, deportaciones: así impacta la covid-19 a migrantes». Pie de Página. Recuperado de https://piedepagina. $\mathrm{mx} /$ hipernacionalismo-cierre-de-fronteras-deportaciones-asi-impacta-la-covid -19-a-migrantes/

Rea, D. (4 de junio de 2020). «Migrantes en América sufren hipernacionalismo, cierre de fronteras y deportaciones». Inter Press Service (IPS). Recuperado de https://ips noticias.net/2020/06/migrantes-america-sufrren-hipernacionalismo-cierre -fronteras-deportaciones/

Reina, E. (21 de marzo de 2020). «Los migrantes varados en México, desarmados frente al coronavirus». El País. Recuperado de https://elpais.com/internacional/2020-03-20/ los-migrantes-varados-en-mexico-desarmados-frente-al-coronavirus.html

Reza, A. y Barquet, D. (19 de mayo de 2020). «Proveedores del Pentágono y un bloque de armadoras, reabren». Milenio. Recuperado de https://www.milenio.com/politica/ reabren-proveedores-pentagono-bloque-sector-automotriz

Rodríguez, E. (2012) Extranjeros en México. Continuidades y nuevas aproximaciones. México: INM-DGE. 
Roldán, U. (2017). "La frontera estratégica y extendida, México-Centroamérica. Sus impactos: sseguridad nacional versus derechos humanos de la población migrante»». En Ares, A. y Eriguren, J. (eds.), Los movimientos migratorios en las fronteras iberoamericanas. Madrid: Observatorio Iberoamericano sobre Movilidad Humana/ Migraciones y Desarrollo/Pontificia Universidad de Comillas.

Ruiz, C.E. y Martínez, G. (enero-junio 2015). «Comercio informal transfronterizo México-Guatemala desde una perspectiva de frontera permisiva». Estudios Fronterizos, 16(31).

Ruiz, V. y Varela, A., (enero-junio 2020). «Caravanas de migrantes y refugiados en tránsito por México: el éxodo de jóvenes hondureños que buscan, migrando, preservar la vida». EntreDiversidades, 7(14), pp. 92-129.

Secretaría de Gobernación (2020). Boletín Estadístico de la Unidad de Política Migratoria, 2012-2020. México: Secretaría de Gobernación.

Sieff, K. y Miroff, N. (21 de abril de 2020). «U.S. is deporting infected migrants back to vulnerable countries». Washington Post. Recuperado de https://www.washingtonpost. $\mathrm{com} /$ world/the_americas/us-is-deporting-infected-migrants-back-to-vulnerablecountries /2020/04/21/5ec3dcfe-8351-11ea-81a3-9690c9881111_story.html

Snell, K. (26 de marzo de 2020). «What's inside the senate's $\$ 2$ trillion coronavirus aid package». Npr. Recuperado de https://www.npr.org/2020/03/26/821457551/ whats-inside-the-senate-s-2-trillion-coronavirus-aid-package

The Associated Press (8 de septiembre de 2020). "Mexico diverted money from development to contain migration». Recuperado de https://apnews.com/article/virusoutbreak-donald-trump-caribbean-international-news-united-states-16cbd1780d 18298df9f7fd272fc1e53f

The UN Refugee Agency (UNHCR) (s/f). Estadísticas de población, series de tiempo. Recuperado de http://popstats.unhcr.org/en/persons_of_concern

The U.S. Department of State (2020). «2020 Investment Climate Statements: Mexico». Recuperado de https://www.state.gov/reports/2020-investment-climate-statements /mexico/

Torliere, M. (1 de abril de 2020). «Testimonios desmienten la versión del INM sobre el motín de Tenosique». Proceso. Recuperado de https://www.proceso.com.mx/nacional /2020/4/2/testimonios-desmienten-la-version-del-inm-sobre-el-motin-de-teno sique-240778.html

Torre, E. y Mariscal, D.M. (2020). «Batallando con fronteras: estrategias migratorias en tránsito de participantes en caravanas de migrantes». Estudios Fronterizos, 21. https://doi.org/10.21670/ref.2005047 
Wolf, M. (2018). Fire and fury. Inside the Trump White House. Estados Unidos: Henry Holt and Company.

Wolf, S. (2020). La migración forzada desde el Triángulo Norte de Centroamérica. Impulsores y experiencias. México: Centro de Investigación y Docencia Económicas.

Woodward, B. (2020). Rage. Estados Unidos: Simon \& Schuster.

Velazco, J. (2016). La derecha radical en el Partido Republicano. De Reagan a Trump. México: Fondo de Cultura Económica.

Velásquez, M. (13 de septiembre de 2020). «Estadounidenses experimentan en carne propia los inconvenientes que tienen los latinoamericanos: su pasaporte se devalúa y enfrentan más restricciones». Yahoo Noticias. Recuperado de https://es-us. noticias.yahoo.com/la-devaluacion-del-pasaporte-estadounidense-covid-trump $-142737453 . h t m l$ 